\title{
Sala Virtual de Física: uma alternativa para apoiar e complementar o ensino presencial de Física
}

\author{
Eduardo Mendes ${ }^{1,2}$, Márcia Cristina Moraes ${ }^{3}$ \\ ${ }^{1}$ Centro de Ensino Vinicius de Moraes, Natal, MA, Brasil \\ ${ }^{2}$ Centro de Ensino Rio Grande do Norte, Natal, MA, Brasil \\ ${ }^{3}$ Pontifícia Universidade Católica do Rio Grande do Sul, Porto Alegre, RS, Brasil \\ scmaedu@yahoo.com.br, marcia.moraes@pucrs.br
}

\begin{abstract}
Resumo. Este trabalho apresenta a construção de uma Sala Virtual de Física, que é uma alternativa de baixo custo a um Ambiente Virtual de Aprendizagem, para apoiar e complementar o ensino presencial de Física sobre o assunto Movimento Periódico Oscilações. Tendo como fundamentação especialmente a Teoria de Aprendizagem Significativa de Ausubel e os princípios da aprendizagem colaborativa, a Sala Virtual utiliza ferramentas baseadas em plataformas Web 2.0 e Objetos de Aprendizagem (com foco em simulações de Física) disponíveis gratuitamente na Internet. Acreditamos que esta iniciativa possa servir de exemplo para professores, em especial de Física, que queiram desenvolver ambientes virtuais alternativos similares.
\end{abstract}

Palavras-chaves: Sala Virtual de Física, Web 2.0, Objetos de Aprendizagem, Simulações

\section{Virtual Classroom of Physics: An alternative to support and complement the presential teaching of Physics}

\begin{abstract}
This paper presents the construction of a Virtual Classroom of Physics, which is a low cost alternative to a Virtual Learning Environment to support and complement teaching on the subject of Physics Periodic Movement - Oscillations. Considering the Theory of Meaningful Learning of Ausubel and principles of collaborative learning, the Virtual Classroom uses tools based on Web 2.0 platforms and Learning Objects (with a focus on simulations of Physics) available free on the Internet. We believe this initiative can serve as an example for teachers, especially Physics, who want to develop alternative virtual environments.
\end{abstract}

Keywords: Virtual Classroom of Physics, Web 2.0, Learning Objects, Simulations

\section{Introdução}

Atualmente, na Rede Estadual do Maranhão, a carga horária semanal da disciplina de Física no Ensino Médio, nos turnos matutino e vespertino, é de três aulas no primeiro e terceiro anos e duas aulas no segundo ano, sendo considerada muito pequena para o volume de conteúdos que constam nos livros didáticos e que são exigidos nos vestibulares e ENEM (Exame Nacional do Ensino Médio). Por isso, há a necessidade de ampliar o tempo e espaço de aprendizagem da Física nesta etapa do Ensino Básico. 
Em todos os anos do Ensino Médio, os professores sempre priorizam certos conteúdos em detrimento de outros, uma escolha que varia muito conforme as concepções de cada docente em relação ao currículo de Física, nem sempre resultando em uma escolha boa para os alunos. Uma maneira de contornar este problema, sem depender de ampliação da carga horária escolar presencial, seria estender as aulas de Física para além do seu limite temporal habitual. Isto é possível com o uso de Tecnologias de Informação e Comunicação, mais propriamente a Internet, através de aulas virtuais a distância.

Atualmente, encontram-se disponíveis na Internet diversas plataformas, especialmente desenvolvidas para a educação a distância, que favorecem a criação de ambientes virtuais de aprendizagem e permitem desenvolver cursos virtuais, utilizando largamente recursos interativos de ensino e permitindo a construção do conhecimento de forma colaborativa.

Contudo, o Ensino Médio da Rede Estadual do Maranhão, assim como da maioria das redes de ensino brasileiras, funciona através de aulas exclusivamente presenciais, não dispondo de um ambiente de aprendizagem virtual formal e organizado para apoiar e complementar as aulas presenciais. Por não haver a estrutura oferecida pelo poder público, quase sempre os professores deixam de utilizar a Internet no planejamento das suas aulas, por não conhecerem um meio viável e prático de fazê-lo.

Para preencher esta lacuna no Ensino Médio e propiciar um exemplo para ser usado por professores, em especial de Física, apresentamos a construção de uma Sala Virtual de Física (SVF) - uma alternativa de baixo custo a um Ambiente Virtual de Aprendizagem (AVA) - para apoiar o ensino presencial de Física sobre o assunto Movimento Periódico - Oscilações, a partir da utilização de ferramentas baseadas em plataformas Web 2.0 e de Objetos de Aprendizagem (com foco em simulações de Física) disponíveis gratuitamente na Internet.

Entretanto, não se trata do emprego de uma plataforma educacional especialmente desenvolvida para tal fim, como, por exemplo, a plataforma Moodle, mas da utilização de diversas ferramentas online com recursos Web 2.0, de uso geral e não restrita à educação, de modo que o professor, com certa flexibilidade, possa desenvolver sua Sala Virtual de Física (um "ambiente virtual de aprendizagem" alternativo), de forma relativamente fácil e a baixo custo, adequando-se à realidade dos professores de escolas públicas.

A Sala Virtual de Física desenvolvida foi aplicada em duas turmas de duas escolas públicas de São Luís. Os alunos participaram das atividades propostas no ambiente virtual e responderam a questionários e testes.

O artigo está organizado em seis seções. A segunda seção apresenta o referencial teórico. A terceira seção indica como o referencial teórico foi aplicado na Sala Virtual de Física (SVF). A quarta seção descreve a SVF. A quinta seção apresenta o estudo de caso realizado e a última seção apresenta uma análise dos dados e as considerações finais.

\section{Referencial Teórico}

Nesta seção iremos apresentar o referencial teórico utilizado para a realização do trabalho.

\subsection{Aprendizagem Significativa e Aprendizagem Mecânica}


O presente trabalho se fundamenta, primordialmente, na Teoria da Aprendizagem Significativa, a qual procura explicar os mecanismos internos que ocorrem na mente humana com relação ao aprendizado e à estruturação do conhecimento. Segundo Ausubel [Masini 1994], há duas formas limites e opostas de aprendizagem: a aprendizagem mecânica e a aprendizagem significativa. No entanto, o espectro de aprendizagem não é discreto, cada aprendizado pode se situar em um contínuo entre o mecânico e o significativo. Ausubel afirma que a aprendizagem é mais significativa à medida que a nova ideia ou conceito é incorporado às estruturas de conhecimento do aluno e adquire significado para ele, de forma não-arbitrária e substantiva, a partir da relação com seu conhecimento prévio. Por outro lado, a aprendizagem é mais mecânica ou repetitiva quando possibilita menos incorporação e atribuição de significado, fazendo com que a nova ideia ou conceito passe a ser armazenado isoladamente ou por meio de associações arbitrárias, de modo literal, na estrutura cognitiva [Masini 1994].

Para Ausubel, o termo estrutura cognitiva tem o significado de uma estrutura hierárquica de conceitos [Rosa 2010], uma edificação mental ordenada, sendo considerado o conteúdo total e organizado de ideias de um dado indivíduo ou de certos assuntos de determinada área do conhecimento. De acordo com [Rosa 2010]: "A estrutura cognitiva de cada indivíduo é extremamente organizada e hierarquizada, no sentido que as várias ideias se encadeiam de acordo com a relação que se estabelece entre elas. Além disso, é nesta estrutura que se ancoram e se reordenam novos conceitos e ideias que o indivíduo vai progressivamente internalizando, aprendendo."

Em geral, para que a aprendizagem ocorra de forma, realmente, significativa, Ausubel indica dois fatores essenciais, descritos por Moreira(2012): "O material deve ser potencialmente significativo e o aprendiz tem que manifestar uma disposição para aprender. A primeira dessas condições implica em que o material tenha significado lógico e que o aprendiz tenha disponíveis, em sua estrutura cognitiva, subsunçores específicos com os quais o material seja relacionável."

\subsection{Aprendizagem Colaborativa}

A aprendizagem colaborativa é um recurso educativo fundamentado na colaboração. Ela é essencialmente interativa, na qual os membros do grupo ajudam e confiam uns nos outros, trabalhando conjuntamente para atingir um objetivo determinado e consenso comum entre eles. Em situação de aprendizagem por colaboração, cada membro desenvolve, compartilha um objetivo comum e sua compreensão dos problemas, questões, ideias e soluções; além de responder aos questionamentos, ideias e soluções dos outros. Cada um contribui com o seu conhecimento, estando o processo de ensino-aprendizagem descentralizado, sem distinções hierárquicas, envolvendo tanto professor/aluno quanto aluno/aluno, ou seja, abrangendo todos aqueles que fazem parte do grupo de aprendizagem [Dillenbourg et al. 1996].

A aprendizagem colaborativa tem no ambiente virtual um meio propício para sua efetivação, devido à agilidade e à flexibilidade deste recurso tecnológico no que se refere a tempo, espaço e possibilidades de escolhas de percursos. Com computadores ligados em rede, comunidades virtuais de aprendizagem podem ser criadas, permitindo a interação entre os membros do grupo, de maneira síncrona e assíncrona, principalmente, a distância. 


\section{Aprendizagem Significativa e Colaborativa na Sala Virtual de Física}

Uma Sala Virtual de Física, da maneira como foi implementada, utilizando recursos similares aos encontrados em um Ambiente Virtual de Aprendizagem, em tese deve contribuir para a aprendizagem significativa e colaborativa. Neste sentido, o material de estudo organizado e disponibilizado na Sala Virtual de Física pretende ser potencialmente significativo para o aprendiz, por possuir relação com o que o aluno já conhece: o assunto havia sido explanado semanas antes na sala de aula presencial (servindo como organizadores prévios para os conceitos a serem revistos na sala virtual). Além disso, os exemplos de movimentos periódicos, como a oscilação de um balanço de parque infantil e o movimento dos ponteiros de um relógio, fazem parte do cotidiano dos alunos e revelam alguns subsunçores que dão significados à aprendizagem do conteúdo.

Em termos de colaboração, buscamos utilizar ferramentas interativas que permitem a interatividade aluno-computador, através de hipertexto e simulações interativas em Applet Java e Objetos de Aprendizagem em Flash; e interatividade aluno-aluno e aluno-professor, através de fóruns de discussão, chats, correio eletrônico, blogs e editores colaborativos.

\section{Descrição e Estruturação da Sala Virtual de Física}

\section{1. Composição da Sala Virtual de Física}

A Sala Virtual de Física (SVF) foi desenvolvida com o software eXe - eLearning XHTM editor ${ }^{l}$ (aplicativo utilizado geralmente para construção e reutilização de Objetos de Aprendizagem [eLearning 2012] e [KonRath 2009]) e utiliza ferramentas colaborativas e Objetos de Aprendizagem. A SVF foi hospedada em um servidor gratuito, $\quad \mathrm{O} \quad Z_{y m i c}{ }^{2}, \quad$ no endereço http://tubafisica.zxq.net/salavirtual/movperiod/index.html (a Figura 1 mostra a página inicial da Sala Virtual de Física).

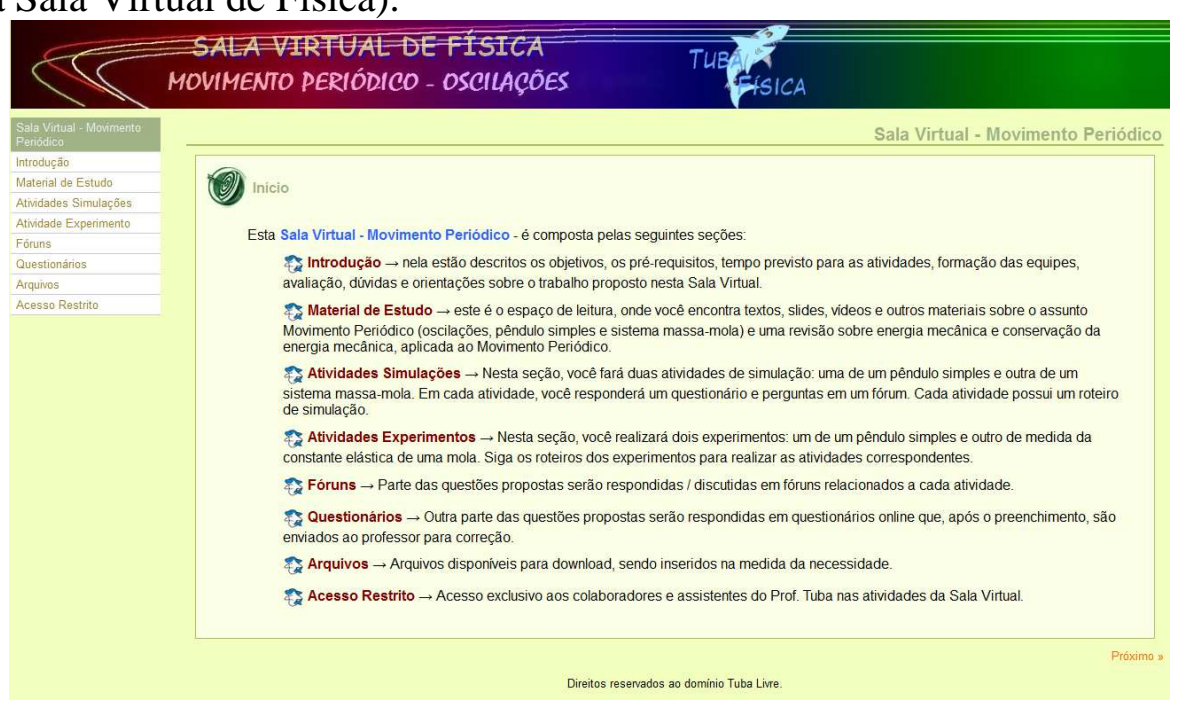

Figura 1 - Página inicial da Sala Virtual de Física hospeda no servidor Zymic

\footnotetext{
${ }^{1}$ http://exelearning.org/wiki

${ }^{2}$ http://www.zymic.com/

V. $10 \mathrm{~N}^{\mathrm{o}} 3$, dezembro, 2012
} 
A página inicial da SVF possibilita o acesso do aluno as seguintes seções: introdução, material de estudo, atividades simulações, atividades experimentos, fóruns, questionários, arquivos e acesso restrito.

Na seção "Introdução" são descritos os objetivos, os pré-requisitos, o tempo previsto para realizar as atividades, as informações sobre a formação das equipes, a avaliação, as dúvidas e orientações sobre as tarefas propostas.

$\mathrm{Na}$ seção "Material de Estudo" estão disponíveis os materiais que foram divididos em quatro tópicos: Movimento Periódico - Definição; Pêndulo Simples; Sistema Massa-Mola e Energia no Movimento Periódico, contendo textos, figuras, fotos, animações, slides e arquivos em PDF, sendo parte deles hospedados no servidor do Zymic e o restante nos sites de origem, estes exibidos na Sala Virtual de Física através de frames.

Na seção "Atividades Simulações" estão disponíveis as duas atividades de simulação propostas: uma de um pêndulo simples e outra de um sistema massa-mola. Em cada atividade, os alunos devem responder a um questionário e às perguntas em um fórum.

Na seção "Atividades Experimentos" estão disponíveis dois experimentos: Pêndulo Simples e Pêndulo de Vela.

Todas as atividades (de simulação e de experimentos) a serem desenvolvidas pelos alunos possuem um roteiro a ser seguido, indicando como deve ser realizada a atividade.

Na seção "Fóruns" os alunos têm acesso aos fóruns disponíveis na SVF. No roteiro de cada atividade, existem questões que devem ser respondidas e discutidas no respectivo fórum da atividade. Além dos fóruns de discussão, estão disponíveis: um fórum em formato de blog (Blog do Fórum) para publicação de notícias sobre o desenvolvimento das atividades e comunicados gerais; um Fórum de Dúvidas para esclarecer as dúvidas dos alunos sobre o funcionamento da Sala Virtual e um chat. A seção Fóruns foi desenvolvida utilizando a plataforma Web 2.0 do site Forumeiros.com, que permite a criação de fóruns de forma flexível, com inúmeras configurações.

$\mathrm{Na}$ seção "Questionários" os alunos têm acesso aos questionários online, relacionados às atividades, que deveriam ser respondidos e enviados ao professor para correção. Os questionários foram elaborados utilizando o gerador de formulários do Google Docs ${ }^{3}$, que possui uma planilha eletrônica associada. Após responder ao questionário completo e enviá-lo, o aluno recebia uma mensagem de agradecimento, indicando que o formulário preenchido foi enviado com sucesso para correção. Porém, o aluno não poderia recuperar os dados enviados e modificá-los, pois a ferramenta não permite tal operação. As respostas dos usuários são registradas na planilha eletrônica associada, que foi configurada para emitir uma notificação ao professor quando houvesse uma nova postagem.

Na seção "Arquivos" são disponibilizados aos alunos arquivos complementares, de textos ou outros materiais, para download. Os alunos têm a possibilidade de inserir conteúdo neste espaço de compartilhamento da Sala Virtual, que funciona como uma espécie de portfólio coletivo. A seção "Arquivos" foi criada usando outra ferramenta colaborativa, baseada em plataforma Web 2.0, denominada Zoho Notebook ${ }^{4}$. Neste

\footnotetext{
${ }^{3}$ http://docs.google.com

${ }^{4}$ https://notebook.zoho.com

V. $10 \mathrm{~N}^{\mathrm{o}}$ 3, dezembro, 2012
} 
aplicativo, que faz parte do suite Zoho, é possível compartilhar arquivos distintos (imagens, elementos áudio visuais, arquivos HTML, url, arquivos PDF, etc.), escrever em um mural de avisos, conversar por chat, entre outros recursos. Devido às suas características, funcionou na Sala Virtual como um porta-arquivos funcional e flexível, permitindo o download de materiais complementares disponibilizados pelo professor e pelos alunos.

Na seção "Acesso Restrito" o professor e os alunos colaboradores do professor nas atividades da SVF tinham acesso aos arquivos de registro e acompanhamento de atividades realizadas. Nesta seção foi utilizado outro aplicativo da plataforma Zoho, o Zoho Sheets ${ }^{5}$, planilha eletrônica colaborativa utilizada pelo professor para gerenciar o cadastramento dos alunos no site Forumeiros.com e registrar a participação geral deles na Sala Virtual. O acesso à planilha era restrito aos colaboradores das turmas, que auxiliavam o professor neste trabalho.

Como se pode observar, muitos recursos existentes em um AVA, como espaço para disponibilização de materiais de estudo diversos (textos, ilustrações, slides, áudios, vídeos, animações, simulações, etc.), blog interno, fóruns de discussão, bate-papo eletrônico, questionários online e portfólio, estavam presentes na Sala Virtual de Física, embora de forma limitada, principalmente, no que tange a recursos de avaliação.

\subsection{Descrição das Atividades Propostas}

As atividades propostas foram de dois tipos: Atividades de Simulações (ATV1 e ATV2) e Atividades de Experimento Reais (ATV3 e ATV4). Cada atividade era acompanhada de um roteiro da atividade, com questões que privilegiam a interpretação de texto e o raciocínio lógico e que devem ser respondidas no Questionário Online ou no Fórum correspondente.

- ATV1 - Atividade 1 - Pêndulo Simples: Nesta atividade, os alunos realizam a simulação de um Pêndulo Simples através de um simulador em Flash (disponível na Internet e acessado pelos alunos através da SVF) (Figura 2), guiado pelo Roteiro de Simulação do Pêndulo Simples. Em seguida, respondem ao Questionário ATV1 e às perguntas do Fórum ATV1, conforme orientações que constam no roteiro da atividade.

- ATV2 - Atividade 2 - Sistema Massa-Mola: Nesta atividade, os alunos realizam três simulações de um Sistema Massa-Mola, seguindo o Roteiro da Simulação Sistema Massa-Mola e utilizando o Simulador 1 (um applet Java que simula um sistema massa-mola sem atrito - Figura 3), Simulador 2 (animação em Flash, que simula um sistema massa-mola com atrito - Figura 4) e Simulador 3 (animação em Flash, que compara um sistema massa-mola com um pêndulo simples - Figura 5). Todos os três simuladores são Objetos de Aprendizagem disponíveis na Internet e acessados através da SVF. Após usar os simuladores, os alunos respondem ao Questionário ATV2 e às perguntas do Fórum ATV2, conforme orientações que constam no roteiro da atividade.

- ATV3 - Experimento Pêndulo Simples: O objetivo desta atividade era a montagem de um experimento real de um pêndulo simples. Seguindo o Roteiro do Experimento do Pêndulo Simples, os alunos devem medir a frequência própria de oscilação para diversos comprimentos de pêndulo. De posse do valor da frequência, devem calcular o período próprio de oscilação do pêndulo

\footnotetext{
${ }^{5}$ http://sheets.notebook.com

V. $10 \mathrm{~N}^{\mathrm{o}} 3$, dezembro, 2012
} 
simples. Em seguida, comparar os valores obtidos no experimento com os calculados teoricamente; determinar a aceleração da gravidade local e, por último, verificar a independência da massa na frequência. Os resultados obtidos devem ser publicados em uma planilha compartilhada do Google Docs, sendo editada colaborativamente. Ao final, devem responder a uma questão no Fórum ATV3.

- ATV4 - Desafio do Pêndulo de Vela: Orientados pelo Roteiro do Desafio do Pêndulo de Vela, opcionalmente os alunos podem construir um experimento pitoresco utilizando uma vela e duas taças. $\mathrm{O}$ experimento deve ser filmado, usando qualquer dispositivo que produza vídeos (filmadora, câmera digital ou celular) e divulgar o vídeo em um compartilhador de vídeos como o YouTube e, finalmente, incorporá-lo no Fórum ATV4, aberto a comentários sobre o vídeo produzido e explicações sobre o fenômeno descrito. Este experimento, por ser uma tarefa relativamente mais complicada, tinha caráter opcional.

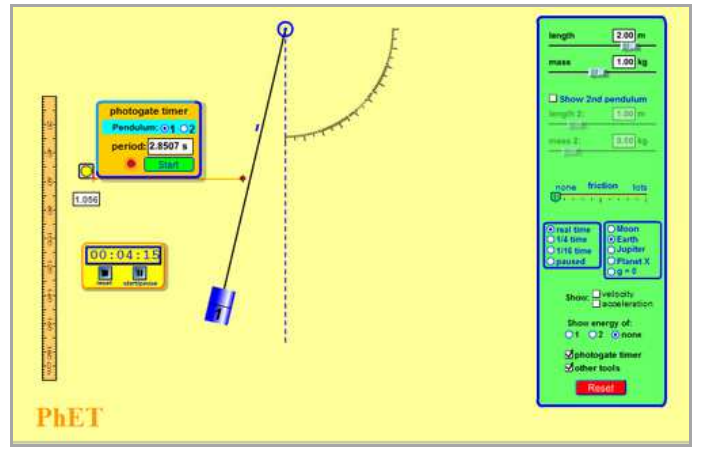

Figura 2 - Simulador Pêndulo Simples

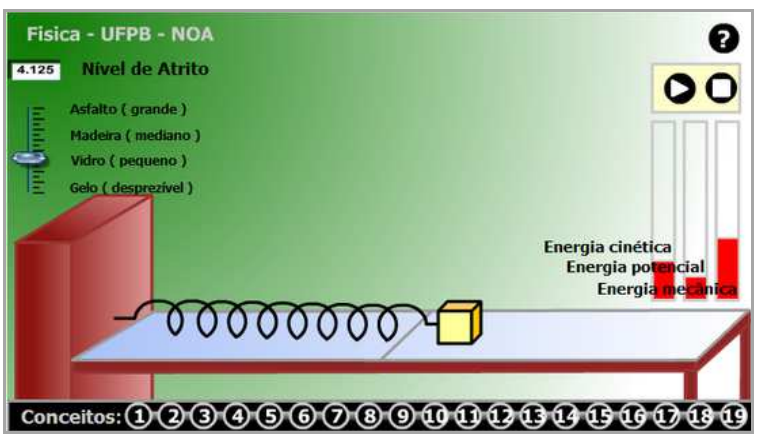

Figura 4 - Simulador 2 - Sistema Massa-Mola com atrito

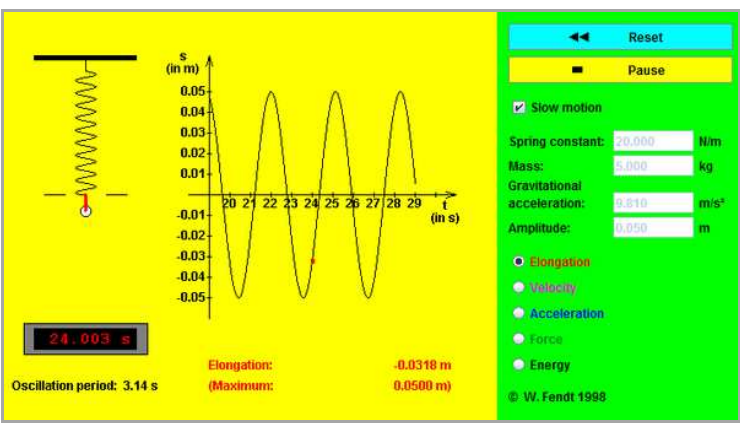

Figura 3 - Simulador 1 - Sistema Massa-Mola sem atrito

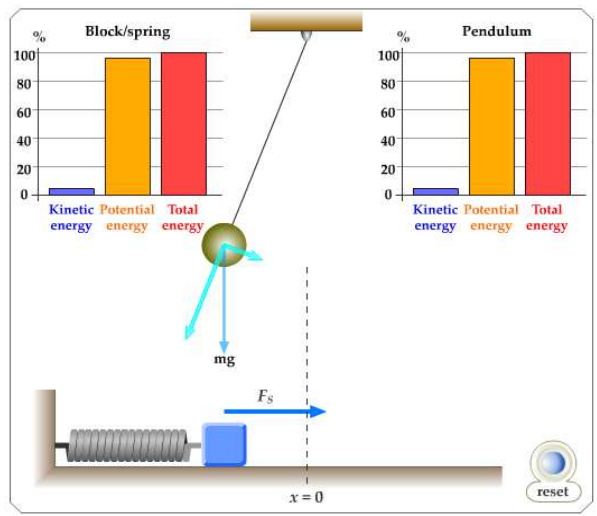

Figura 5 - Simulador 3 - Sistema MassaMola versus Pêndulo Simples

\section{Estudo de Caso}

O estudo foi realizado com alunos de duas turmas do terceiro ano do Ensino Médio do Centro de Ensino Vinicius de Moraes (Escola A), as duas com 29 alunos cada, e por alunos de outras duas turmas também do terceiro ano do Ensino Médio do Centro de Ensino Rio Grande do Norte (Escola B), uma turma com 30 e a outra com 45 alunos, pertencentes à Rede Estadual do Maranhão, localizadas na capital São Luís.

As aulas ocorreram na modalidade a distância, de modo a complementar as aulas presenciais de Física, durante 41 dias com início no dia 13 de agosto de 2011 e 
encerramento no dia 23 de setembro. O professor acompanhou as turmas a distância, servindo como mediador no processo ensino-aprendizagem.

As aulas podiam ser acessadas em qualquer local com computador e acesso à Internet, podendo ocorrer na escola, em casa ou em outro lugar. Como o acesso na escola era difícil, pois os laboratórios de informática estavam em manutenção ou funcionando precariamente no período da pesquisa, quem não tivesse acesso doméstico e precisasse usar uma $L A N$ house, teria que arcar com as despesas. Por causa disto, optou-se em não exigir obrigatoriedade na participação na Sala Virtual de Física. Por outro lado, isto permitiu medir o grau de motivação em participar das aulas virtuais e as razões que impediram uma parte dos alunos de participar das atividades na Internet.

As atividades propostas na Sala Virtual deveriam ser realizadas, preferencialmente, em equipe de três alunos, aceitando-se duplas, se não fosse possível formar trios. Em situações singulares, com a aprovação do professor, as atividades podiam ser feitas individualmente, porém, foram evitadas ao máximo. $\quad$ O trabalho em grupo era necessário por motivos técnicos (limitação das ferramentas utilizadas, dificuldades de controle e gerenciamento), econômicos (dificuldades dos alunos para acesso a computador e Internet) e devido à falta de conhecimentos de informática de muitos alunos que, em grupos, poderiam resolver parte das dificuldades encontradas.

Para auxiliar o professor na tarefa de orientar os grupos na operacionalização da Sala Virtual de Física, foi escolhido em cada turma um aluno colaborador, que também seria o moderador do Fórum, selecionado entre aqueles com maior domínio de informática. O colaborador-moderador recebia maiores instruções do professor a distância ou presencialmente e mantinha maior contato com este, servindo de mediador e auxiliar no desenvolvimento das aulas virtuais.

A formação das equipes, instruções gerais sobre o agrupamento e cadastros das equipes nos sites Web 2.0 utilizados no trabalho aconteceram na sala de aula presencial. As aulas a distância foram precedidas de um mês de aulas presenciais sobre o mesmo assunto de Física: Movimento Periódico - Oscilações.

Na sala de aula presencial, houve apenas quatro aulas relacionadas à Sala Virtual de Física: uma aula para os alunos responderem ao pré-teste e pré-questionário da pesquisa; uma aula para apresentação da SVF através de datashow (foi mostrada apenas uma visão panorâmica do ambiente); uma aula para divisão das equipes e apoio ao cadastramento no Fórum; e, após o fechamento da Sala Virtual, houve uma aula para os alunos responderem ao pós-teste e pós-questionário.

O objetivo do pré-questionário e pós-questionário foi medir, essencialmente, a motivação em participar da Sala Virtual de Física, respectivamente, antes e depois das aulas virtuais. O pré-teste e o pós-teste foram aplicados com o intuito de medir o conhecimento sobre o assunto estudado antes da aplicação da Sala Virtual, ou seja, após as aulas expositivas presenciais e depois de acontecer o ensino a distância.

\section{Análise dos Dados e Considerações Finais}

O pré-questionário possuía oito perguntas fechadas e visava medir o grau de motivação dos alunos em estudar Física ou a motivação de estudar Física através de aulas virtuais na Internet; saber quais recursos didáticos utilizados pelos professores despertam mais a atenção dos alunos; qual a frequência com que os professores utilizam o computador como ferramenta didática; com que frequência os alunos acessam Internet e de que locais e, ainda, quem possui computador em casa com acesso à rede mundial. 
Analisando os dados obtidos pelo pré-questionário, constatamos que 41,9\% dos alunos gostam de estudar Física; 14,3 \% não gostam de estudar Física e 43,8 \% são indiferentes. Os dados mostram que $43,8 \%$ dos alunos sentem-se motivados em estudar Física; $18,1 \%$ não se sentem motivados e $37,1 \%$ são indiferentes.

Em relação ao interesse em estudar Física por meio de aulas virtuais, 42,9 \% dos alunos possuem um interesse maior em participar de aulas virtuais de Física, aulas no computador através da Internet, $24,8 \%$ possuem nenhum ou pouco interesse, enquanto que $31,4 \%$ possuem um interesse mediano por esta modalidade de ensino.

Em relação ao uso do computador, $46,7 \%$ dos alunos não possuem computador em casa; por outro lado, 41,0 \% possuem computador com acesso à Internet, enquanto que $11,4 \%$ têm computador sem Internet. 35,2 \% dos alunos responderam que acessam a Internet sempre, com muita frequência. Mas 64,8 \% não entram na Internet com regularidade, fazem isso raramente ou esporadicamente. São os que, em tese, teriam mais dificuldades para participar da Sala Virtual de Física. É interessante observar que ninguém declarou que nunca acessa a Internet, mesmo existindo um percentual significativo de jovens no Maranhão sem acesso à rede mundial de computadores [Brito 2012].

Contendo nove perguntas fechadas e oito perguntas abertas, o Pós-Questionário visava medir qual foi o grau de participação dos alunos na Sala Virtual de Física; o grau de motivação na realização do trabalho; se o participante gostou das atividades; o que mais chamou a atenção na Sala Virtual; quais foram as dificuldades na realização das tarefas e quais as expectativas em relação a outros trabalhos virtuais.

A participação das atividades da SVF foi de 40,1\%. Este dado leva em conta as respostas dos alunos e não à participação real na Sala Virtual, conferida pelas tarefas realizadas e enviadas ao professor para correção. Houve aluno que, inicialmente, participou da Sala Virtual, mas não concluiu nenhuma atividade. Portanto, a participação real das turmas, medida pelo registro das atividades entregues pelos grupos, mostram valores um pouco menores: houve a participação real de 27,6 \% dos alunos. Em relação a esta baixa participação, a maioria, 29,5\%, alegou que "Houve dificuldades de acesso a computador e Internet", mesmo para quem possuía computador em casa. Em segundo lugar, 18,2 \% responderam que "Houve problemas com tempo para a realização das atividades - falta de tempo para realizar a atividade", ou atividade muito longa que exigia muito tempo, tornando o acesso à Internet caro para quem dependia de LAN house. Em terceiro lugar, a alegação mais frequente foi "Por preguiça, desmotivação - falta de interesse" $(15,9 \%)$, mostrando que o trabalho não foi motivador para estes alunos, a ponto de vencer a apatia de quem está cansado de aulas tradicionais. A desmotivação pode ter ocorrido também devido à dificuldade de acesso à Internet e à falta de hábito para lidar com novas tecnologias. Uma análise mais profunda da pesquisa poderia mostrar que a exclusão digital impossibilita a maior participação de alunos em aulas a distância. Em quarto lugar aparecem as respostas agrupadas no item "Houve dificuldades operacionais no uso das ferramentas da Sala Virtual - problemas com softwares" $(12,1 \%)$.

A análise dos dados mostra que $42,1 \%$ dos alunos sentem-se nem motivados nem desmotivados em estudar Física através de aulas virtuais; enquanto que 34,6\% sentem-se mais desmotivados que motivados e apenas $21,5 \%$ sentem-se mais motivados que desmotivados. 
Comparando com a questão do pré-questionário, que media o grau de interesse dos alunos por aulas virtuais de Física, vemos que o interesse inicial era maior do que o interesse registrado após o fechamento da SVF. As observações não-estruturadas e a análise dos questionários revelam que isto, provavelmente, aconteceu devido às dificuldades que os alunos tiveram em termos de acesso a computador e à Internet e problemas de operacionalização da Sala Virtual. A frustração de não poder participar ativamente das aulas virtuais deve ter sido o principal motivo que fez diminuir a motivação e expectativa inicial. Isto fica evidente quando analisamos o grau de motivação por participação efetiva ou não na SVF: 32,0 \% de motivação entre os que participaram e 18,3 \% entre os que não participaram. Os números apontam que o grau de motivação entre os que participaram da Sala Virtual é expressivamente maior do que entre os que não participaram. Ainda assim, esperávamos um grau de motivação maior dos que haviam participado das aulas no ambiente virtual.

Embora a motivação tenha diminuído, é importante ressaltar que, dos alunos que participaram efetivamente da SVF, 64,0\% responderam que gostam da ideia de que suas aulas de Física no Ensino Médio sejam complementadas com aulas na Internet; 36,0 \% são indiferentes e ninguém respondeu que não gostaria de ter mais aulas virtuais. Este resultado indica que a maioria dos alunos que participou da Sala Virtual de Física gostaria de participar de outras aulas de Física pela Internet, através de um sistema similar ao que foi usado neste estudo.

Como trabalhos futuros estamos aperfeiçoando algumas das ferramentas disponibilizadas na Sala Virtual de Física, a fim de utilizá-la com novos alunos no início do próximo ano letivo.

\section{Referências}

BRITO, D. $40 \%$ dos estudantes brasileiros não têm acesso à internet, mostra pesquisa. Folha Online. Disponível em: <http://www1.folha.uol.com.br/folha/educacao/ult305u665109.shtml>. Acesso em: 18/02/2012.

DILLENBOURG, P.; BAKER, M.; BLAYE, A.; O'MALLEY, C. The evolution of research on collaborative learning. In E. Spada; P. Reiman (Eds) Learning in Humans and Machine: Towards an interdisciplinary learning science. Oxford: Elsevier, 1996, p. 189-211.

ELEARNING XHTML EDITOR. Disponível em: <http://exelearning.org/wiki>. Acesso em: 12/02/2012.

KONRATH, M. L. P.; RODRIGUES, A ; TAROUCO, L. M. R. ; MEZZARI, A. Autoria e empacotamento de conteúdos. Revista Novas Tecnologias na Educação, v. 7, p. 1-10, 2009.

MASINI, E. F. S. (Org.). Psicopedagogia na escola: buscando condições para a aprendizagem significativa. São Paulo: Loyola, 1994.

MOREIRA, M. A. Subsídios teóricos para o professor pesquisador em ensino de ciências: A Teoria da Aprendizagem Significativa. Disponível em: <http://www.if.ufrgs.br/ moreira/Subsidios6.pdf>. Acesso em 15/03/2012.

ROSA, P. R. S. Instrumentação para o Ensino de Ciências. Campina Grande: Editora da UFMS, 2010. 